\title{
Literacidad crítica y literacidades digitales: ¿una relación necesaria?
}

\section{(Una aproximación a un marco teórico para la lectura crítica)}

\section{Critical Literacy and Digital Literacies: A Necessary Relationship?}

Alfonso Vargas Franco ${ }^{1}$

\section{Resumen}

En este texto se argumenta que la literacidad digital exige la literacidad crítica (lectura crítica) como una condición sine qua non para la construcción de significado de la cultura escrita. El artículo tiene como propósito aportar en la construcción de un andamiaje teórico para comprender las nuevas dimensiones de la literacidad crítica en la enseñanza de las prácticas letradas contemporáneas mediadas por las tecnologías digitales. Se analiza también en las más recientes pruebas de ingreso a la universidad colombiana (ICFES, Saber 11. ${ }^{\circ} .2014$, “Ejemplos de preguntas") un componente inédito hasta el momento en este tipo de exámenes: lectura crítica. Finalmente, se seleccionó uno de los ejemplos de preguntas de las Pruebas ICFES Saber $11 .^{\circ}$ con el propósito de evidenciar si se aplican estrategias de lectura crítica o si prevalecen las estrategias derivadas de las concepciones lingüística y psicolingüística, dominantes en la enseñanza de la comprensión de lectura. Los resultados del análisis permiten concluir que estas perspectivas continúan siendo privilegiadas en este tipo de pruebas.

\section{Palabras clave}

Literacidad crítica, lectura crítica, literacidades digitales, formación de lectores críticos, sociedad de la información.

\section{Abstract}

In this paper it is argued that critical literacy is required by digital literacy (critical reading) as a sine qua non condition in order to build meaning of written culture. This text aims to help to establish the theoretical framework to understand the new dimensions of critical literacy in the instruction of contemporary practices given through the digital technologies. In the current national state examination (ICFES, Saber 11), a new component: Critical Reading was analyzed. Sample questions were chosen in order to determine if critical reading strategies are applied or if the known strategies belonging to the dominating linguistics and psycholinguistic assumptions are still assumed in the reading comprehension instruction. The results of the analysis allow us to conclude that these latter perspectives are still being adopted in these types of examinations.

Key words

Critical literacy, critical reading, digital literacies, training critical readers, information society.

Artículo recibido el 6 de octubre de 2014 y aprobado el 7 de abril de 2015

1 Universidad del Valle, Cali, Colombia. Correo electrónico: alfonso.vargas@correounivalle.edu.co 


\section{Introducción}

Resulta indiscutible afirmar que la emergencia de lo digital ha producido transformaciones sin precedentes en la forma de circulación, procesamiento y apropiación de la información y el conocimiento. Las prácticas letradas contemporáneas han experimentado también unos cambios vertiginosos. Hoy se lee más, en diversos formatos y con nuevos géneros discursivos que combinan texto escrito, imagen y sonido. Es lo que Kress (2003) denomina la multimodalidad, la cual pareciera ser una característica distintiva de los textos que circulan en internet y las redes sociales. La lectura en papel se combina ahora con una variedad de prácticas de lectura en dispositivos móviles (tabletas, teléfonos celulares, computadores portátiles, etc.); pero también en pantallas fijas en diferentes escenarios públicos (la pantalla de un cajero automático, las pantallas que muestran itinerarios del transporte público en las grandes ciudades, las pantallas de los vuelos en los aeropuertos, etc.) y privados (videojuegos, chats, videoconferencias, compartir textos y fotos en las redes sociales, la lectura online de una gran variedad de géneros discursivos multimodales, compras de diversos tipos de artículos en Internet, reservas de cine, así como espectáculos culturales y deportivos, etc.). Ya lo había planteado McLuhan hace más de cuarenta años en relación con los medios masivos de comunicación como la televisión:

El medio, o proceso, en nuestra época - la tecnología electrónica- está moldeando y reestructurando los modelos de interdependencia, así como cada aspecto de nuestra vida. Esto nos está exigiendo reconsiderar y reevaluar prácticamente cada pensamiento, cada acción, y cada institución que habíamos dado por acabadas. Todo está cambiando, tu familia, tu educación y tu vecindario, tu trabajo, tu gobierno, tu relación con los "otros". Todo está cambiando dramáticamente. (McLuhan, 1967, p. 8)

Barton y Lee (2013) defienden que estos cambios, relacionados con la incidencia de las tecnologías digitales en diferentes esferas de la vida humana, están ligados con complejos cambios sociales. La vida contemporánea está modificándose de múltiples maneras, las cuales tienen un impacto significativo sobre el lenguaje y las prácticas comunicativas. Varios autores (Delors, 1996; Coll, 2005; Barton y Lee, 2013; Montero, 2014; Rizvi y Lingard, 2013; Lankshear y Knobel, 2010 Kress, 2003) coinciden en su análisis sobre la incidencia de la internacionalización y la globalización de la economía neoliberal en los cambios de la sociedad contemporánea, su estrecha correlación con la expansión de las tecnologías digitales y los nuevos modos de generación y transmisión de conocimientos. Por su parte, Kress (2013) considera que no es posible reflexionar sobre la literacidad de manera aislada de una amplia gama de factores sociales, tecnológicos y económicos.

Así, los cambios que había vaticinado de manera visionaria McLuhan, se multiplican de manera vertiginosa con las nuevas tecnologías digitales. Hoy se reconoce que muchos aspectos de la vida social, de la vida privada y del mundo laboral, así como los procesos de enseñanza y aprendizaje son transformados por las tecnologías digitales. Las voces que hablaban de la muerte del libro y del fin de la lectura son contrastadas con las de quienes argumentan que se encuentra lejos de agotarse el proyecto emancipador que está implícito en la lectura. Al contrario, en el contexto de la sociedad de la información y el conocimiento esta se ha diversificado, complejizado y multiplicado con las tecnologías digitales de la información:

La lectura ha sido, es y continuará siendo uno de los instrumentos principales, si no el principal, de acceso al conocimiento, y nada hace prever que esta situación vaya a cambiar con las tecnologías digitales de la información y la comunicación. (Coll, 2005, p. 5).

Los cambios derivados de un nuevo entramado social y político mediado por las tecnologías digitales han tenido repercusiones en los diferentes niveles educativos. La universidad ha resultado también afectada por nuevos modos de apropiación y circulación del saber y de su legitimación, así como por las demandas de eficacia que imponen las multinacionales, los gobiernos y la sociedad civil. Sin embargo, 
se ha estudiado poco - y tampoco es el objetivo de este artículo- la relación entre las tecnologías digitales, las comunidades científicas y los procesos de construcción de conocimiento en las instituciones de educación superior en el contexto de los profundos cambios que hemos venido exponiendo.

Pons (2010) y Vargas (2015a) plantean que la incorporación de las tecnologías digitales en la educación superior exige a la universidad proponerse unos nuevos objetivos en relación con los procesos de enseñanza y aprendizaje en el contexto de la sociedad de la información y del conocimiento. Otros autores, como Martínez (2012) y Gewerc (2014), sostienen que las economías basadas en el conocimiento sitúan a la universidad en un lugar destacado para su desarrollo, por lo cual se plantean preguntas relacionadas con la relevancia del conocimiento, su proceso de construcción y circulación, su legitimación y sus potenciales beneficiarios. No obstante, estos últimos autores no se ocupan de la relevancia de las tecnologías digitales en la apropiación y circulación del conocimiento en la educación superior.

También, la escritura académica también ha experimentado significativos cambios (Barton y Lee, 2013). En primer lugar, ya no escribimos sobre hojas de papel, sino que plasmamos directamente nuestras ideas en esquemas y borradores previos a través de los procesadores de textos; utilizamos diccionarios en red, consultamos artículos e investigaciones en Google, escribimos correos a investigadores para obtener datos para construir estudios e investigaciones, tenemos acceso a muy variados recursos de edición en forma simultánea (diferentes fuentes tipográficas, herramientas para dibujar tablas y esquemas, numeración de páginas, diseño de páginas, márgenes, columnas). Solo basta observar la barra de herramientas de Word para darnos cuenta de todas estas posibilidades.

El mismo proceso de revisión sufre modificaciones sustanciales en relación con las anotaciones, tachaduras y diverso tipo de observaciones que se hacían en el papel. Incluso, la corrección ortográfica que brinda Word cuando repara de manera inme- diata una palabra mal escrita ortográficamente o cuando marca con rojo el error son herramientas con las que no contaban los escritores de textos académicos hasta hace solo algunas décadas. Sin embargo, la escuela y la educación superior en nuestro país siguen siendo refractarias a estas profundas transformaciones en los modos de leer y escribir en la era de Internet y de las redes sociales.

\section{Hipótesis de trabajo}

La hipótesis que queremos someter a prueba en este artículo es, por un lado, que la dimensión crítica de la lectura o la lectura crítica (literacidad crítica) constituye un componente esencial de la formación de lectores contemporáneos y, por el otro, que debe ser un objeto de enseñanza e investigación en todos los niveles educativos porque es una dimensión a través de la cual se exploran los nuevos modos de leer en la sociedad de la información y el conocimiento. También, de acuerdo con el punto de vista sociocultural y crítico, estar alfabetizado implica mucho más que saber cómo está conformado el sistema lingüístico y cómo usarlo (Lankshear y Knobel, 2010).

Las denominadas literacidades digitales o alfabetismos digitales (esta última denominación, de acuerdo con las traducciones a la lengua castellana de los conceptos fundamentales de los trabajos de los nuevos estudios de literacidad) requieren usos intensivos y más complejos de la lectura. En primer lugar, por la gran cantidad de información; en segundo lugar, por la diversidad de fuentes o sitios web desde los cuales se descargan contenidos; en tercer lugar, por la escasa fiabilidad de muchos de ellos; y finalmente, por los sesgos ideológicos de muchas páginas web en los cuales se vehiculan contenidos sexistas, machistas, racistas, homofóbicos, neonazis, de extrema derecha, fundamentalismos religiosos, etc., los cuales reproducen ideologías dominantes y formas de abuso del poder, además de contenidos que incitan al consumo y la banalidad. También en Internet y las redes sociales se expresan grupos que se oponen al poder, los cuales se posicionan dentro de luchas de resistencias contra la hegemonía 
económica y cultural. Nos referimos a los grupos afros, indígenas, colectivos gay, colectivos urbanos, grafiteros, músicos alternativos, grupos de izquierda radical, etc.

Estos fenómenos requieren una gran capacidad de discernimiento y análisis por parte de los nuevos lectores, unas facultades críticas potentes para no sucumbir ante la avalancha de información, para saber navegar con "timón crítico":

En Internet, sí. En Internet está todo lo que somos capaces de producir los humanos, sin censura ni límites ni fronteras políticas: las investigaciones de Science o Nature al lado de arengas de charlatanes de feria; los datos empíricos y contrastados con los obsoletos o especulativos; las webs honestas junto con los panfletos políticos; los foros ingenuos junto con propaganda, pornografía o virus. En definitiva: lo bueno y lo malo. Cualquiera puede colgar una web, enviar una contribución a un foro o intervenir en una enciclopedia pública virtual, sin cumplir ninguno de los criterios que impone un periódico para publicar una carta de sus lectores, un boletín para difundir una investigación o una editorial para publicar un libro. En Internet la basura y el fango se mezclan con las perlas y las joyas. Ésta es la grandeza y la flaqueza de la red. (Cassany, 2006, p. 220-221)

En este artículo adoptamos el término literacidades que proviene del inglés literacy (reading and writing) cuya traducción a la lengua castellana sería alfabetismo o alfabetización. De acuerdo con Cassany (2006), alfabetización es un término demasiado vinculado con el alfabeto y connota una concepción mecánica de la lectura y la escritura. También se relaciona con la educación formal, con la escolarización, lo cual resulta limitante. Aún más, arrastra con significados negativos como analfabeto o analfabetismo y connotaciones concomitantes como inculto, ignorante, de acuerdo con el diccionario de María Moliner (2007).

El concepto literacidades evita estos prejuicios. Es más neutro y se acerca más a las denominaciones sobre la cultura escrita en otras lenguas. Además, no resulta extraño desde el punto de vista etimológico y cultural porque se relaciona con palabras como letrado, literal, literalidad, literatura o literario. En otras palabras, conserva el sema letra que constituye el fundamento de la cultura escrita y evoca todos sus poderes. Otro aspecto que resulta de interés es la pertinencia de la pluralización literacidades para reconocer la multiplicidad de formas de leer y escribir contemporáneas. Además, admite otros vocablos como biliteracidad (leer y escribir en dos idiomas), multiliteracidad (leer y escribir en varios idiomas), literacidad crítica (lectura y escritura críticas). Por otra parte, el término literacidad/literacidades permite conectar mejor con una serie de investigaciones emprendidas desde la perspectiva de los nuevos estudios de literacidad (new literacy studies), las cuales vienen estudiando las prácticas letradas vernáculas y dominantes en contextos escolares y extraescolares desde una dimensión sociocultural y crítica. No obstante, en forma reciente se vienen empleando los términos Nuevos estudios sobre la lengua escrita y Nuevos Estudios de Cultura Escrita (NLS).

\section{Lo crítico. Fundamentos teóricos}

A lo largo del artículo empleamos nociones como lectura crítica o literacidad crítica (lectura y escritura críticas) para referirnos a un componente esencial de la cultura escrita contemporánea. Sin esta dimensión crítica o criticidad, la lectura y la escritura en la sociedad de la información y el conocimiento no cumplirían cabalmente su función. En otras palabras, la literacidad crítica (lectura y escritura críticas) significa la capacidad de seleccionar y filtrar grandes cantidades de información, la capacidad de analizar su veracidad y rigor, la habilidad de contrastar las fuentes y los enfoques que se dan a los datos, la facultad de interpretar los contextos, los nuevos roles de lector y escritor, y la de evitar ser manipulados por los discursos que circulan en los medios, en Internet y las redes sociales y de producir textos propios con los recursos que ofrece la red. Exploramos a continuación, un marco teórico para contribuir en la formación de lectores y escritores críticos. 


\section{Metáforas para comprender las prácticas letradas contemporáneas}

Expondremos algunas metáforas que ayudan a comprender lo que Prensky (2012) denomina el más grande desafío al cual nos enfrentamos los educadores en este nuevo contexto de cambio, variabilidad e incertidumbre en la era digital. Por otra parte, y como consecuencia de estas profundas transformaciones que Chartier (2001, p. 6) denomina una "mutación epistemológica fundamental", se está produciendo un cambio de orientación del proceso educativo, centrado tradicionalmente en el profesor hacia el estudiante como productor activo del conocimiento.

Este desplazamiento del foco del profesor hacia el foco del estudiante en la educación contemporánea supone retos muy importantes para los profesores, las políticas educativas y, por supuesto, para los propios alumnos que están en una zona de pasividad. La criticidad a la hora de leer y escribir constituye no solo un requerimiento formal en las prácticas letradas contemporáneas, sino un nuevo paradigma, esencial para sobrevivir en un universo en el que los desajustes cognitivos y socioculturales que plantea el uso intensivo de las tecnologías digitales serán cada vez más profundos y a los cuales hay que enfrentar con éxito en la enseñanza de la cultura escrita.

Lo que puede resultar aún más paradójico es que buena parte del aprendizaje de los nativos digitales o de los niños y jóvenes de la era digital se produce más allá de las fronteras de la escuela. Se trata, en todo caso, de un aprendizaje informal mediado por la relación con pares, la Internet, Youtube, la televisión, los videojuegos, teléfonos móviles y una gran provisión de sitios web como las aplicaciones (apps) utilizadas para la información y el entretenimiento, las cuales pueden ser seleccionadas de manera autónoma por los usuarios de las tecnologías digitales. El desplazamiento del lugar central del profesor hacia el lugar del alumno (sus necesidades, deseos y voces) requiere en cualquier caso, una pedagogía del acompañamiento. En esta concepción, el uso de la tecnología es trabajo del estudiante. El trabajo del profesor se orienta a la enseñanza y guía en el uso de la tecnología para el aprendizaje eficaz. Al hacerlo, los docentes necesitan enfocarse, más que ser expertos en las tecnologías, en prácticas habituales dentro de su trabajo que incluyen formular buenas preguntas, proveer contextos, garantizar el rigor y evaluar la calidad del trabajo del estudiante (Prensky, 2010).

Pero se presenta de nuevo otra paradoja: para que haya más éxito en el uso de las tecnologías dentro del aula no se requiere que los profesores aprendan ellos mismos a usarlas (aunque es deseable que ellos también desarrollen procesos de alfabetización tecnológica). Prensky (2010), considera que lo que los profesores necesitan conocer es, precisamente, cómo la tecnología puede ser usada por los estudiantes para mejorar su propio aprendizaje.

\section{Nativos e inmigrantes digitales}

Los nativos digitales, la provocadora metáfora creada por Marc Prensky (2001) para referirse a los jóvenes que nacieron conectados a la red y han crecido en medio de pantallas, dispositivos móviles y redes sociales (YouTube, Facebook, Twitter, Instagram, Flickr, etc.) es uno de los constructos que mejor define las necesidades a las que debe responder la educación del siglo xxi. Prensky (2001) se preguntaba cómo llamar a los "nuevos" estudiantes de hoy. Pensó inicialmente en la letra N (por net) o en la $\mathrm{D}$ (por digital), por último encontró que la definición más útil era la de digital natives (nativos digitales). En contraste, quienes no nacimos dentro del mundo digital, y lo hicimos en un momento tardío de este, pero que hemos sentido fascinación por adoptar muchos de los aspectos de las tecnologías digitales (y que siempre somos comparados con ellos), nos denominaríamos digital inmigrants (inmigrantes digitales).

La importancia de esta distinción, a juicio de Prensky, radica en que todos los inmigrantes, algunos mejor que otros, para adaptarse al nuevo ambiente digital, siempre conservan en alguna medida, una "huella" en su pasado. Fueron "socializados" en forma diferente a sus hijos, y se encuentran ahora en el proceso de aprendizaje de un nuevo 
lenguaje. Y se trata, además, de un lenguaje aprendido de forma tardía en la vida.

El problema radica en que los profesores inmigrantes digitales, quienes enseñan en un lenguaje, obsoleto o pasado de moda, es decir, de la era predigital, están luchando para enseñar a una población que habla fundamentalmente un nuevo lenguaje: "Our students have changed radically. Today's students are no longe the people our educational system designed to teach" (Prensky, 2001, p. 1).

La pérdida del papel hegemónico de la escuela en la apropiación y circulación de la información y el conocimiento es evidente en este nuevo entorno de las tecnologías digitales. El carácter fragmentario de la información ejerce una fuerte influencia en el desarrollo social y cognitivo de los niños, porque introduce valores y concepciones ideológicas monitoreadas o controladas a través de formas de interpretar la realidad y orientar la toma de decisiones. En contraposición a este carácter reproductor de la cultura dominante, la educación debe representar hoy un espacio de cambio, "cumpliendo la función de reelaborar crítica y reflexivamente la cultura" (Libâneo, 2013, p. 10).En definitiva, los profundos cambios que están experimentando la educación como consecuencia de la expansión de lo digital plantean desafíos inéditos a los profesores, a las políticas públicas, a los currículos, y en particular a la enseñanza y aprendizaje de los nuevos modos de leer y escribir en el siglo xxi.

\section{Residentes y visitantes digitales}

Cassany (2012) retoma no solo esta metáfora, a partir de Kruse (2010), sino que nos ofrece una alternativa provocadora a la metáfora de Prensky, al plantearla en términos de residentes y visitantes digitales. El visitante digital es la persona que solo se conecta de vez en cuando para revisar el correo o buscar información ocasional. En otras palabras, el visitante digital considera que la Red es algo diferente de la realidad.

Al contrario, los residentes digitales viven inmersos en la Red: se comunican en forma permanente a través de WhatsApp, Facebook y Twitter, com- parte video de Youtube, cuelgan fotos en Instagram, leen periódicos y revistas en línea y poseen lo que Cassany (2012) denomina una "identidad digital" plena.

\section{El origen del componente crítico de la lectura. Enfoques sociales y culturales}

Una de las dimensiones más importantes de estos nuevos aprendizajes a los que se enfrentan a diario los estudiantes de la era digital es el desarrollo de la criticidad. Por esta razón, el objetivo de este apartado es explorar las relaciones entre los enfoques dominantes sobre la lectura y el desarrollo del componente crítico en la lectura. Consideramos que los enfoques sobre la lectura se han centrado básicamente en la concepción lingüística, luego en la concepción psicolingüística y, de un tiempo acá, han dado lugar a una ruptura epistemológica con los enfoques socioculturales y críticos. La primera concepción ponía el énfasis en la decodificación de lo escrito, una especie de traducción de lo escrito en discurso oral; la segunda concepción plantea que la lectura es un proceso más complejo que exige la implementación de procesos cognitivos e implica, entre otras actividades, la activación de los conocimientos previos del lector, establecer hipótesis sobre el texto, negociar los significados con el escritor, reconstruir la macroestructura semántica del texto, etc. Cassany (2006) denomina a este conjunto de habilidades o destrezas alfabetización funcional. En consecuencia, cuando una persona no es capaz de extraer el significado global de un texto puede considerarse como un analfabeto funcional.

Sin embargo, son muchos los factores que inciden en una nueva conceptualización de los procesos de lectura y escritura. Podríamos enumerar los más relevantes. Entre estos se encuentran la expansión de las tecnologías digitales, la divulgación del conocimiento científico a través de la prensa escrita y digital, la irrupción de las redes sociales como Facebook y Twitter, la transformación de la prensa escrita en prensa digital, los cambios democráticos que se están experimentando en todo el mundo, entre otros fenómenos impensables hasta hace algunas décadas. 
Estos cambios exigen una nueva aproximación al fenómeno de la comprensión que había sido considerado el presupuesto básico de los enfoques psicolingüísticos. Leer hoy es más diverso y complejo. La naturaleza del texto escrito ha cambiado, como lo conocíamos en sus diferentes formatos en papel, y ha migrado hacia nuevos soportes que integran imagen, sonido, $y$, sobre todo, han posibilitado nuevos e impredecibles trayectos de lectura a través de los hipertextos. La lectura no es solo decodificación o la comprensión literal, sino que requiere bucear más allá, indagando, por ejemplo, en los significados implícitos y, lo que es más importante en estos tiempos donde circulan vastas cantidades de información en internet y en las redes sociales, ser capaz de seleccionar la información relevante dentro de toda la basura textual a la que nos vemos expuestos, identificar las verdaderas intenciones de los autores, los sesgos y prejuicios, en resumen, la ideología de los textos.

En otras palabras, no basta con comprender, sino que se requiere ir mucho más allá de lo que encierran las palabras en el texto escrito, escudriñar aspectos como el contexto en el cual el autor produjo el documento, las circunstancias sociales e históricas que rodearon este acto de producción, las condiciones que rodean la recepción del texto, la identidad del autor, la identidad del lector. Por ejemplo, desde qué dimensión geopolítica se construye un texto narrativo o un texto científico. No es lo mismo escribir un texto desde la órbita de las culturas hegemónicas, etnocentristas, anglosajonas a hacerlo desde los países de la periferia; desde un lugar institucional de la academia como la universidad, a hacerlo desde una wiki o blog; desde una disciplina de las ciencias exactas a hacerlo desde las ciencias humanas y sociales; desde una postura individual o en representación explícita de un colectivo social. No solo leemos textos escritos en papel, sino que interactuamos a diario con la lectura en las pantallas de dispositivos móviles como el teléfono celular, los computadores portátiles, las tabletas, en una oficina, en un aula de clase, en un cibercafé, etc.
Todas estas dimensiones del fenómeno de la lectura en tiempos de la posmodernidad o de la modernidad líquida (Bauman, 2006, 2010) requieren el desarrollo de una competencia crítica que englobe las dimensiones lingüística, psicolingüística y sociocultural. La diversificación de la lectura, la gran cantidad de información que circula en Internet, los nuevos formatos textuales que integran video, música, texto e imagen, la variedad de fuentes y de recursos (diccionarios en línea, correctores, formatos para la edición, etc.) están transformando nuestra relación con la cultura escrita y han difuminado las fronteras entre lo académico y lo vernáculo, entre lo público y lo privado, entre la autoría individual y la autoría colectiva. También los blogs, las wikis y las redes sociales se han convertido en un gran entramado textual en los circulan una multiplicidad de discursos hegemónicos y contrahegemónicos, frente a los cuales hay que tomar posición como lectores y escritores.

En consecuencia, los enfoques lingüísticos y psicolingüísticos resultan insuficientes para explicar los retos de la lectura contemporánea. Por esta razón, la concepción sociocultural y crítica de la lectura puede contribuir a entender estas nuevas dimensiones del proceso de comprensión para retar el que se había constituido en el paradigma dominante de la cultura escrita: la perspectiva psicolingüística. La perspectiva sociocultural y crítica de la lectura (literacidad crítica o alfabetización crítica) plantea, entre otros presupuestos, que el discurso escrito no es neutral ni objetivo, y que por el contrario, es el resultado de condicionamientos ideológicos que influyen sobre la selección del tipo de texto, la estructura, la retórica, la organización semántica, la disposición espacial, el diseño y la tipografía, entre otros aspectos. Por otra parte, atribuye un papel relevante a los usos y formas particulares que adopta la lectura en cada contexto (Cassany, 2006).

Tejada y Vargas (2007) afirman que la complejidad de los actos de leer y de escribir es de tal magnitud que la explicación de la naturaleza de estos procesos tiende a ser cada vez más multi e interdisciplinaria. Estos autores reconocen que la fusión 
de disciplinas como la lingüística y la psicología cognitiva en la psicolingüística han sido los enfoques que tradicionalmente se han ocupado de los procesos de lectura y escritura y constituyen una visión dominante en el campo, hasta tal punto que tanto en el desarrollo teórico como en las prácticas de enseñanza, prevalecen los análisis lingüísticos o textuales, los procesos cognitivos en el nivel del individuo $\mathrm{y}$, de manera más reciente, los estudios e investigaciones sobre la interacción texto-lector.

Ahora bien, es necesario reconocer los aportes de la psicolingüística a las prácticas de enseñanza de lo letrado, en forma particular en el desarrollo de la literacidad funcional (destrezas y habilidades de lectura y escritura, comprensión de inferencias, activación de conocimientos previos y reconocimiento del tipo de texto, etc.).

En su artículo, estos investigadores plantean, sin embargo, las limitaciones del enfoque psicolingüístico porque no ha abordado el análisis sobre las consecuencias que tienen los factores sociales y culturales en los procesos de lectura y escritura. Estos factores han sido objeto de estudio de algunas corrientes de la sociología, de la pedagogía, de los estudios culturales y de algunos enfoques literarios que propenden por la formación del lector, en contraposición a las visiones historiográfica y han centrado su interés en la literacidad crítica. Por esta razón, consideran que se hace necesario integrar la dimensión social y cultural a los aspectos lingüísticos y psicológicos. En resumen, se requiere integrar la literacidad funcional, la literacidad cultural y la literacidad crítica. El problema se ha complejizado por la expansión de un nuevo tipo de literacidades: las literacidades digitales.

\section{Otros enfoques: la teoría literaria}

Existen antecedentes y teorías que convergen o, dicho de otro modo, son predecesoras de los enfoques socioculturales y críticos de la lectura y contribuyen a expandir sus posibilidades. Nos referimos al análisis crítico del discurso y la teoría del hipertexto. A partir de los trabajos de Barthes (1980) y Derrida (2005), que anticiparon con sus estudios muchas de las transformaciones de la lectura que sobrevendrían con la irrupción de las tecnologías digitales, se produce un cambio de paradigma en relación con la estructura del texto y su manera de ser abordado por el lector. Al postular un texto abierto se sientan las bases de lo que se conoce como hipertexto electrónico. Lo que Barthes (1980) define como ideal de la textualidad es un texto conformado en una organización de redes que no tienen una relación jerárquica entre sí, sino que es una "galaxia de significantes y no una estructura de significados" (Barthes, 1980, p. 3) que no tiene un principio, pero sí diversos caminos de acceso, es un texto abierto, absolutamente plural:

Interpretar un texto no es darle un sentido (más o menos fundado, más o menos libre), sino por el contrario apreciar el plural del que está hecho. Tomemos primero la imagen de un plural triunfante que no esté empobrecido por ninguna obligación de representación (de imitación). En este texto ideal las redes son múltiples y juegan entre ellas sin que ninguna pueda reinar sobre las demás; este texto no es una estructura de significados, es una galaxia de significantes; no tiene comienzo; es reversible; se accede a él a través de múltiples entradas sin que alguna de ellas puedas ser catalogada con toda seguridad la principal, son indecibles (el sentido no está nunca sometido a un principio de decisión sino al azar); los sistemas de sentido pueden apoderarse de este texto absolutamente plural, pero su número no se cierra nunca, al tener como medida el infinito del lenguaje. (Barthes, 1980, p.3).

Por su parte, Foucault (2009) sostiene que "las fronteras de un libro nunca están claramente definidas", ya que movilizan en este un sistema de referencias a otros libros, otros textos, otras frases, "es un nodo dentro de una red [...] una red de referencias" (citado en Landow, 1995, p. 15). En una perspectiva más contemporánea, Mendoza (2012) distingue entre hipertextos digitales e hipertextos en papel, para distinguir los soportes, lo cual es útil para comprender las posibilidades de incluir hipervínculos con referencias multimodales y de ensanchar su textualidad con mayor o menor complejidad. 
Como plantea Landow (1995), son varias las coincidencias o afinidades entre la teoría del hipertexto y la teoría crítica. La teoría crítica (Barthes, 1980; Foucault, 2009) permitió anticipar la teoría del hipertexto, mientras que el hipertexto permite demostrar varios aspectos de la teoría, de manera particular los relacionados con la textualidad narrativa, y a las funciones de lector y escritor. Con el hipertexto, los exponentes de la teoría crítica cuentan con dos posibilidades: la primera con un tipo de laboratorio donde poner a prueba sus ideas, y la segunda, las bibliotecas tradicionales de textos escritos. La teoría del hipertexto encarna los conceptos posestructuralistas de texto abierto: "Lo que es antinatural en la letra impresa se vuelve natural en el ámbito electrónico y muy pronto no hará ni falta decirlo, porque podría mostrarse" (Bolter, 1990, p. 143).

De acuerdo con este autor, el hipertexto es un texto compuesto de fragmentos de texto - que Barthes designa con el nombre de lexias-y los nexos electrónicos que los conectan entre sí.

En definitiva, el hipertexto de acuerdo con Landow es un "texto compuesto de bloques de palabras (o de imágenes) electrónicamente unidos en múltiples trayectos, cadenas o recorridos en una textualidad abierta, eternamente inacabada y descrita con términos como nexo, nodo, red, trama y trayecto" (1995, p. 14).

Esta definición capta en esencia la dinámica textual que ha adquirido el discurso escrito en los tiempos de Internet y las redes sociales, modificando el estatuto epistemológico de la lectura y la escritura que prevaleció durante el período de preeminencia del texto escrito en papel y en las aproximaciones más cognitivas.

\section{El análisis crítico del discurso (ACD)}

Ahora examinaremos el papel del análisis crítico del discurso en la expansión de las posibilidades del enfoque sociocultural de la lectura y la escritura. El análisis crítico del discurso (ACD) es un campo interdisciplinario (pragmática, análisis del discurso, sociolingüística, etnografía de la comunicación, teoría de la argumentación) que básicamente se ocupa de analizar las relaciones de dominación, discriminación, poder y control, tal como se expresan a través del discurso. En otros términos, el ACD tiene como propósito investigar de manera crítica la desigualdad social la cual se expresa, se constituye y se legitima por los usos del lenguaje, esto es, en el discurso (Wodak, 2003). Los conceptos fundamentales del ACD son el concepto de poder, el concepto de historia y el concepto de ideología. Modernamente el poder se expresa a través de la construcción de la legitimación y el consenso en torno al discurso de los poderosos, y no solo a través del uso de la fuerza. Este es uno de los aspectos más interesantes del ACD, y de mayor utilidad para construir un modelo de lectura crítica.

Además, el ACD recupera una serie de nociones de las ciencias del lenguaje que permiten a los lectores analizar con mayor precisión los significados explícitos e implícitos del discurso, sus efectos, el estilo de la prosa, las superestructuras textuales (descriptiva, narrativa, expositiva, argumentativa, etc.), las imágenes de lector y escritor, entre otros aspectos. De manera aún más específica, diversos conceptos del ACD contribuyen en un buen método de aproximación a la lectura crítica, como sostiene Cassany, quien enumera los siguientes: "fuerza ilocutiva, relevancia, esquema de conocimiento, máximas de conversación, cortesía, orientación argumentativa o ideología" (Cassany, 2006, pp. 85-86).

En una vertiente más ligada con la educación, el ACD plantea que el problema del lenguaje y el poder en educación es solo una parte de una problemática social más amplia, y que, por lo tanto, no podría ser visto de manera aislada. Dado que, como lo habíamos manifestado antes, en la época del capitalismo global el poder es fundamentalmente ejercido a través de la manufacturación del consenso; antes que a través de la coerción, a través de la ideología en lugar de la fuerza física; a través de prácticas autodisciplinarias en lugar del uso de la violencia, aunque esto no excluye su uso en gobiernos de facto o democracias fallidas (Fairclough, 2010). 


\section{La conciencia crítica del lenguaje 0 critical language awareness (CLA)}

Las ideas de Fairclough sobre la conciencia crítica del lenguaje contribuyen en la comprensión del proceso mediante el cual el orden social se produce y se reproduce cada vez más a través de prácticas y procesos de orden cultural. En buena medida, este proceso está determinado por un rol cada vez más prominente del lenguaje en el ejercicio del poder. En consecuencia, es a través del discurso que se construye el consenso; a través de este se transmiten las ideologías, así como las prácticas, los significados, los valores y las identidades. Todos estos constructos se enseñan y aprenden en los sistemas educativos.

Sin embargo, en una época de profundos cambios y gran inestabilidad las formas de poder $y$ dominación vienen siendo replanteadas y resistidas también a través de las prácticas discursivas, modificando las prácticas de uso del lenguaje.

Como plantea Fairclough (2010), en años recientes, conceptos como conciencia del lenguaje y el conocimiento acerca del lenguaje han adquirido una creciente importancia en la enseñanza del lenguaje en Gran Bretaña. Se trata de un movimiento alrededor de la conciencia del lenguaje que defiende que esta ha sido escasamente crítica y no ha concedido suficiente atención a los asuntos del poder y del lenguaje que deberían ser estudiados en el lenguaje de la educación. Por esta razón, Fairclough propone una perspectiva de la conciencia crítica del lenguaje (critical language awareness o conciencia crítica del lenguaje, en adelante CLA), en contraposición a las visiones no-críticas. Esta conciencia crítica del lenguaje es también un prerrequisito para la construcción de una verdadera ciudadanía democrática.

Los planteamientos de Fairclough (2010) sobre la CLA son relevantes para la configuración de la literacidad crítica en general, y de la lectura crítica en particular porque revelan que los discursos educativos están atravesados por intereses e ideologías que influyen sobre las prácticas de enseñanza y aprendizaje del discurso escrito. Podemos exponer como corolario de este planteamiento que las exigencias de la sociedad globalizada están propiciando una fuerte demanda a la educación de las habilidades orales, lo cual puede incidir negativamente en un descuido o tergiversación de las funciones de la cultura letrada. Decimos esto sin soslayar la importancia de las habilidades comunicativas orales en la vida cotidiana, en la construcción de la ciudadanía democrática y en la exposición del conocimiento académico.

Fairclough (2010) sostiene que las instituciones educativas están fuertemente involucradas en la marketización (mercantilización) de las prácticas discursivas que constituyen el proceso general más amplio de la marketización institucional, y de las facetas discursivas del proceso sociocultural de la destradicionalización e informalización y tecnologización del discurso como una modo contemporáneo particular de intervención en las prácticas discursivas para dar forma al cambio sociocultural. Las instituciones educativas están, pues, poderosamente influenciadas en el desarrollo que afecta a la lengua general en su relación con el poder. En primer lugar, las propias prácticas educativas constituyen un dominio básico de la lingüística y el poder discursivo y de la ingeniería de las prácticas discursivas. Gran parte de la formación en educación es orientada en gran medida hacia el uso y la inculcación de determinadas prácticas discursivas en las organizaciones educativas, interpretadas más o menos explícitamente como una faceta importante en la inculcación de significados particulares y los valores, las relaciones sociales y de las identidades y las pedagogías. En segundo lugar, muchos otros campos son mediados y transmitidos por las instituciones educativas.

Otro planteamiento de interés en la exposición de Fairclough (2010) es el relacionado con las exigencias del mundo laboral en el contexto del capitalismo posindustrial sobre los discursos y prácticas educativas. En este sentido, se advierte la demanda en la formación de las capacidades dialógicas de los futuros trabajadores, la cual se manifiesta a través de un mayor énfasis en el desarrollo de "habilidades" del lenguaje oral.

En tercer lugar, las instituciones educativas, en mayor o menor medida se encuentran involucradas 
en la educación de la gente acerca del orden sociolingüístico en que las personas viven. En algunos casos, en virtud de la función social y cultural mejorada del lenguaje debido a la tecnologización del discurso, se convierte en un requisito previo esencial para la ciudadanía democrática efectiva, la capacidad de crítica del lenguaje. Sin duda, la crítica del lenguaje se dirige a las prácticas de la propia institución educativa (e incluso en las prácticas críticas en el aula) y hacia las cuestiones de lenguaje y poder en la educación.

Para la construcción del concepto de lectura crítica, el concepto de conciencia crítica del lenguaje de Fairclough permite comprender, en primer lugar, las exigencias que se están haciendo a las instituciones educativas desde la economía de las sociedades posindustriales y del capitalismo finisecular, y cómo las prácticas y discursos educativos terminan reproduciendo este nuevo orden económico mundial. En este orden de ideas, interesa más a las demandas de la sociedad global, el fortalecimiento de las habilidades orales y del trabajo en equipo por encima de la adquisición de habilidades en lectura y escritura críticas que son fundamentales para no sucumbir frente a la avalancha de información de los medios, de las redes sociales y de Internet.

Los cambios que se están produciendo en la esfera económica se ven reflejados en cambios en las necesidades lingüísticas y discursivas determinadas por el trabajo y constituyen, de acuerdo con Fairclough, el principal factor para dar forma o moldear el discursivo educativo en las escuelas. El cambio orientado hacia el sector de los servicios a expensas del sector manufacturero es uno de los elementos que conllevan un enfoque hacia la interacción con el público y clientes. Se produce entonces un énfasis sobre el futuro trabajador como una persona con múltiples habilidades o multiskilled. El trabajo se concibe entonces como la explotación de talentos que no habían sido explotados, incluyendo de los que habían sido considerados como habilidades vitales o existenciales life skills más que habilidades ocupacionales, incluyendo las formas de discurso conversacional.

\section{Freire y el concepto de alfabetización crítica}

Por otra parte, la lectura crítica se ha nutrido de los estudios de Freire y Macedo (1989) sobre alfabetización crítica emancipadora (predecesora de la literacidad crítica contemporánea). Freire critica los enfoques dominantes sobre la lectura. Freire y Macedo (1989) enumeran las siguientes perspectivas predominantes en la lectura:

\section{El enfoque académico de la lectura}

En este enfoque la lectura tiene un doble propósito. Por un lado, la razón de ser de este enfoque radica en las definiciones del hombre bien educado, conocedor en profundidad de los clásicos, un sujeto muy hábil en la expresión oral y escrita y estimulado por los intereses intelectuales. En términos más precisos, la lectura se define como la adquisición de la capacidad de leer, la capacidad de decodificar, y de la adquisición de vocabulario, etc. Como consecuencia de este enfoque se pretende legitimar un orden dual: un nivel para la clase dominante y otro para la mayoría desposeída. Este enfoque resulta altamente alienante porque subyuga la experiencia vital, la historia y el idioma de los estudiantes.

\section{El enfoque utilitario de la lectura}

El propósito principal del enfoque utilitario es formar lectores que respondan a las exigencias básicas de la lectura en la sociedad industrializada. En esta perspectiva se insiste en el aprendizaje mecánico de la capacidad de leer, desdeñando el análisis crítico del orden social y político que determina, en primera instancia, la necesidad de leer. Como consecuencia de este enfoque se forman "personas alfabetizadas funcionalmente", preparadas para satisfacer las demandas de acceso laboral y aumento de la productividad.

\section{El enfoque del desarrollo cognitivo de la lectura}

Este modelo, de acuerdo con Freire y Macedo (1989), concede especial importancia a la construcción de significados, por la cual los lectores constru- 
yen una interacción dialéctica entre ellos mismos y el mundo objetivo. La comprensión del texto es el resultado de la activación de nuevas estructuras cognitivas, de la activación de conocimientos previos del lector, de sus esquemas que le permitirán avanzar desde lecturas simples a lecturas más complejas. En definitiva, la lectura se concibe como un desarrollo intelectual que pasa por etapas de desarrollo fijas, universales y descontextualizadas.

Por otra parte, este enfoque no se ocupa de cuestiones de política cultural porque ignora el patrimonio lingüístico y cultural de los estudiantes, es decir, su experiencia vital, su historia, su identidad y su lenguaje, lo cual impide que se pueda producir una reflexión crítica profunda sobre su propia experiencia para llegar a una comprensión más rigurosa de su significado.

\section{El enfoque romántico de la lectura}

Se basa principalmente en la construcción de sentido en la que se destaca el papel fundamental de lo afectivo y concibe la lectura como una realización del yo y una experiencia lúdica. Constituye un contrapunto con respecto a los modos dominantes de la pedagogía que conciben a los lectores como "objetos". Sin embargo, ignora totalmente el patrimonio cultural de los grupos oprimidos y defiende que el todo el mundo disfruta de las mismas posibilidades de acceso a la lectura, o dicho de otro modo, que la lectura es parte del patrimonio cultural de todas las clases sociales. Si bien defiende la autoestima y la autoafirmación, desconoce que para alcanzar estos logros personales, los estudiantes de las clases trabajadoras se enfrentan a un gran número de desventajas sociales.

\section{La alfabetización crítica emancipadora}

En contraposición con estos enfoques dominantes de la lectura, la alfabetización crítica emancipadora propone, en primer lugar, ir más allá de los enfoques mecánicos, técnicos y descontextualizados de la adquisición de habilidades para recuperar la relación de la lectura con sus contextos ideológicos e históricos.
En consecuencia, el acto de aprender a leer y escribir se concibe como un acto creativo y como uno de los principales medios por los cuales los oprimidos pueden participar en la transformación sociohistórica de la sociedad. En este sentido, la lectura no se reduce solo al aprendizaje mecánico de una técnica, sino que debe ir más allá para contribuir en la comprensión crítica de los objetivos de la reconstrucción de la sociedad.

Así, pues, el desarrollo de una comprensión crítica del texto por parte del lector, y del contexto socio-histórico al cual hace referencia, se constituye en un factor importante de una nueva concepción de la alfabetización. En definitiva, el acto de aprender a leer y escribir es un acto creativo que implica una comprensión crítica de la realidad.

En este marco cobra mucha importancia la relación lectura de la palabra-lectura de la realidad, propia de la epistemología freireana. Ya no existe una separación entre pensamiento-lenguaje y realidad objetiva: "La lectura de un texto exige ahora una lectura dentro del contexto social al cual se refiere" (Freire y Macedo, 1989, p. 84). En esta perspectiva, la alfabetización se fundamenta en una reflexión sobre el patrimonio cultural de los desfavorecidos y se constituye en un medio por el cual los oprimidos construyen los instrumentos básicos para "reapropiarse de su historia, su cultura y su lenguaje" (p. 84).

Para que un programa de alfabetización crítica emancipadora pueda tener éxito en cualquiera de los niveles de la escolaridad se requiere que se lleve a cabo en el idioma del pueblo, sin desconocer que debe haber una apropiación crítica del lenguaje estándar y de sus géneros discursivos para poder entablar un diálogo en términos de igualdad con los diferentes sectores sociales y participar eficazmente en las actividades económicas, culturales y políticas de la comunidad. El creciente acceso de estudiantes provenientes de grupos minoritarios (indígenas, afrodescendientes, obreros, adultos, mujeres cabeza de familia, etc.) representa el cambio de un modelo de educación superior de elite a un modelo de educación más plural, diversificado e incluyente. El modelo de alfabetización crítica de Freire y 
Macedo (1989) constituye un referente importante en la inclusión de un nuevo tipo de estudiante en la universidad (Vargas Franco, 2015b).

\section{Los nuevos estudios de literacidad}

En la segunda mitad del siglo $\mathrm{xx}$, se produjo un conjunto de investigaciones, teorías y aproximaciones que se agrupan bajo el nombre de nuevos estudios sobre literacidad. Desde el punto de vista epistemológico, estos trabajos discuten los conceptos tradicionales de lectura y escritura fundamentados en la perspectiva de la psicología cognitiva y adoptan un enfoque sociocultural (Gee, 1996; Barton, Hamilton e Ivanic, 2000; Cassany, 2006; Aliagas, Castellà y Cassany, 2009; Aliagas, 2011).

Desde un marco multidisciplinario (antropología, etnografía, educación, psicología sociocultural) estos enfoques coinciden en afirmar que la literacidad es una práctica social, localizada en un determinado tiempo y contexto. Así, sostienen que la actividad letrada es la expresión de amplias prácticas sociales. En otras palabras, sugieren desplazar el objeto de estudio de la mente individual y privada a la interacción social y contextualizada en cada comunidad (Cassany, 2006).

Uno de los aportes más relevantes del enfoque de la literacidad - entendida como una práctica social- es que las literacidades están situadas en relación con las instituciones sociales y las relaciones de poder que las sostienen. La educación es una de estas instituciones (Barton, Hamilton e Ivanic, 2000).

En definitiva, la lectura y la escritura son prácticas insertadas en estructuras sociales a las cuales ayudan a dar forma. Sin embargo, no son unidades de comportamiento observables puesto que también implican valores, actitudes, sentimientos y relaciones sociales (Street, 1993). Esto incluye el grado de conciencia de los sujetos sobre la literacidad, las concepciones de literacidad y los discursos sobre la literacidad, cómo las personas hablan sobre estas y construyen sentido sobre la literacidad (Barton, Hamilton e Ivanic, 2000).
Presentamos aquí la teoría de la literacidad como práctica social en forma de una serie de seis enunciados (Barton, Hamilton e Ivanic, 2000, p. 8):

- La literacidad puede ser comprendida, de manera más precisa, como un conjunto de prácticas sociales; estas pueden ser deducidas de los eventos los cuales están mediados por textos escritos.

- Existen diferentes literacidades asociadas con diferentes esferas de vida.

- Las prácticas de literacidad son modeladas por instituciones sociales y relaciones de poder, y alguna son más dominantes, visibles e influyentes que otras.

- Las prácticas de literacidad están inscritas en amplios objetivos sociales y prácticas culturales.

- La literacidad es históricamente situada.

- Las prácticas de literacidad cambian y son frecuentemente adquiridas a través de procesos de aprendizaje informal y construcción de sentido dentro del aprendizaje informal.

\section{La multimodalidad}

De acuerdo con Kress (2003), existen dos factores principales que pueden ayudar a comprender que no es posible pensar la literacidad en forma aislada de un vasto número de factores sociales, tecnológicos y económicos. Por un lado, un amplio movimiento de la actual larga hegemonía de la escritura a la nueva hegemonía de la imagen y, por el otro, el predominio del libro como medio al predominio de la pantalla como medio. Estos dos factores se han combinado produciendo una revolución en los usos y los efectos de la literacidad y de los significados asociados para representar y comunicar en diferentes niveles $y$ en diferentes escenarios. Kress argumenta que el discurso oral seguirá siendo el principal modo de comunicación; el discurso escrito será desplazado cada vez más por la imagen en muchos dominios de la comunicación pública, aunque la escritura continuará siendo el modo de expresión preferido de las élites políticas y culturales. Los efectos com- 
binados sobre la escritura del predominio del modo de la imagen y de la pantalla como medio pueden producirán, a juicio de Kress, profundos cambios en las formas y funciones de la escritura. También esto tendrá profundas consecuencias sobre lo cognitivo, lo afectivo y lo cultural en la relación del hombre con el mundo, así como en las formas y aspectos del conocimiento.

Como sostiene Cassany (2012), el discurso ya no solo contiene letras. También tiene fotos, videos, audio, reproducción virtual, etc. En este sentido, el texto adquiere la característica de ser multimedia o multimodal. Este autor pone como un ejemplo típico una página web (de un hotel, para citar un caso) que incluya los siguientes elementos: una lista de todos los servicios, fotos de las habitaciones, un video corto de las habitaciones y de los exteriores, un mensaje de bienvenida del director, música ambiental, y, en muchos casos, comentarios escritos de valoración de sus servicios por parte de los clientes quienes puntúan con escalas numéricas o de estrellas.

En un plano epistemológico, Kress (2010) argumenta que se está produciendo un cambio en el predomino de la modalidad de la escritura a la modalidad de la imagen, entre otras transformaciones en la cultura del mundo globalizado.

\section{Las literacidades académicas desde una perspectiva crítica}

La escritura académica ha sido un área tradicionalmente asociada a prácticas dominantes de literacidad. Por esta razón explicaremos algunos aspectos nucleares dentro de una concepción crítica de la lectura y la escritura en la universidad.

Dentro de los nuevos estudios de literacidad, se ha formado un área de investigación que se ocupa de la literacidad académica en la educación superior. Los investigadores de esta disciplina han coincidido en afirmar que es erróneo asumir la literacidad como un medio neutral y transparente que sirve para aprender un discurso epistemológicamente transparente (Zavala, 2009; Zavala y Córdova, 2010; Zavala, 2011; Jones, Turner y Street, 1999; Turner, 1999).
Por otra parte, el campo de las literacidades académicas se ocupa del tema de la escritura del estudiante como uno de sus objetos preferenciales. Estos investigadores se apoyan en teorías sociales (Barton, 1994; Gee, 1996; Street, 1984, 1993, 1995; Brice Heath y Street, 2008) y abogan por una mirada más descriptiva y global de la literacidad en contextos académicos y retan el discurso dominante del "déficit" centrado en las "habilidades técnicas" de la escritura.

Más que entrar en debates acerca de la "buena" o "mala" escritura, los etnógrafos examinan la escritura en contextos académicos, como es el caso de los cursos en la universidad, y centran su mirada en el nivel epistemológico. Brice Heath y Street (2008) argumentan que las aproximaciones a la escritura del estudiante y la literacidad en contextos académicos pueden ser conceptualizadas a través de tres perspectivas o enfoques imbricados entre sí:

1. El estudio del modelo de las habilidades.

2. El modelo de la socialización académica.

3. El modelo de las literacidades académicas.

Estos tres modelos están asociados con conceptualizaciones particulares tanto del lenguaje como de la teoría del aprendizaje, cada una con sus propias raíces y tradiciones. Brice Heath y Street $(2008,105-106)$ exponen las diferencias entre estos enfoques.

El modelo del estudio de las habilidades está relacionado con el uso del lenguaje escrito en el nivel de la superficie y se concentra en la enseñanza a los estudiantes de las características formales del lenguaje. Así, por ejemplo, se enseña y aprende el vocabulario, la estructura de las oraciones, la gramática y la puntuación. Este modelo presta escasa atención al contexto e implícitamente está formado por teorías autónomas y aditivas (tales como el behaviorismo) que se relacionan con la transmisión del conocimiento.

En contraste, el modelo de la socialización académica reconoce que los temas de las áreas y las disciplinas usan diferentes géneros y discursos para construir el significado en determinados sentidos 
(cf. Berkenkotter, 1984; Berkenkotter y Huckin, 1995). El modelo de la socialización académica está asociado con el concepto de desarrollo en el constructivismo y el aprendizaje situado que son considerados como marcos organizadores, tanto con el trabajo en sociolingüística, análisis del discurso y la teoría de género.

El modelo de las literacidades académicas recurre tanto a los modelos de habilidades como al de socialización; sin embargo, va más lejos que el modelo de socialización académica al prestar especial atención a las relaciones de poder y autoridad en la construcción de significado e identidad que están implícitas en el uso de las prácticas de literacidad dentro de entornos específicamente institucionales. En gran medida, esta aproximación no ve las prácticas de literacidad centradas exclusivamente en lo disciplinario y en las temáticas de las comunidades, sino que examina cómo las prácticas de literacidad de otras instituciones (por ejemplo, el gobierno, los negocios, la burocracia universitaria, etc.) están implicadas en lo que los estudiantes necesitan aprender y hacer.

Este modelo está influenciado por la lingüística social y crítica (cf. Fairclough, 1992a, 1992b, 2010). También se apoya en las críticas de las teorías socioculturales (Bloome, Power Carter, Morton, Otto y Faris, 2005; Lewis, Enciso y Moje, 2007) las cuales enfatizan en una teoría del aprendizaje que pone en primer plano el poder, la identidad y la agencia en el rol del lenguaje en el proceso de aprendizaje.

Los estudios de las literacidades académicas se benefician especialmente del trabajo etnográfico, porque el trabajo previo sobre lectura y escritura en la educación superior se había centrado en declaraciones prescriptivas, o en unidades técnicas de habilidades diferenciadas. Los etnógrafos que han tomado el espacio de actuación de la educación superior como campo de emplazamiento e investigación, proveen distintas perspectivas que podrían facilitar el desarrollo de nuevas direcciones en teorías prácticas y avances de socialización del lenguaje, para impulsar la idea de un posterior desarrollo del lenguaje. Estos etnógrafos han producido una gran riqueza de relatos que han contribuido tanto a la teoría como a la política (Ivanic, 1998; Jones, Turner y Street, 1999; Lea y Stierer, 1999).

Una de las nociones más importantes del enfoque de la escritura del estudiante en las literacidades académicas tiene que ver con las configuraciones de sentido con las cuales los estudiantes que provienen de grupos históricamente excluidos negocian sus deseos alrededor de su acceso a la universidad y el uso de estos recursos de representación (Lillis, 2001, p. 107).

En otras palabras, lo que las personas desean hacer, ser y significar está fuertemente limitado por las posibilidades y oportunidades que tienen en diferentes contextos de sus vidas diarias, dentro y fuera de la institución universitaria.

\section{Lo "nuevo" de los nuevos estudios de literacidad y de las "nuevas" literacidades}

Como plantean Lankshear y Knobel (2010), los estudiosos e investigadores de la literacidad han venido utilizando las palabras "nuevo" y "nuevos" con "literacidad" y "literacidades". Este fenómeno se ha producido de dos maneras fundamentales que ellos llaman respectivamente paradigmática y ontológica. El concepto paradigmático de "nuevo" surge en el discurso de los nuevos estudios de literacidad (Gee, 1996; Street, 1993). Estos trabajos hacen alusión a un enfoque social y cultural de la comprensión y la investigación sobre la literacidad, y en este sentido pueden considerarse como un nuevo paradigma de investigación en relación con los procesos de lectura y escritura. Una alternativa diferente al paradigma dominante el cual estaba basado en la psicolingüística.

Por su parte, cuando se afirma que los "nuevos" estudios de literacidad son ontológicamente nuevos esto implica asumir que están conformados por un tipo de sustancia diferente de la de los estudios sobre lo letrado que conocimos en el pasado, lo cual significa que se han producido profundos cambios en el carácter y en la sustancia de las nuevas literacidades, relacionados con cambios más amplios en 
las tecnologías, en las instituciones, en los medios de comunicación y la economía, y con la rápida expansión hacia una mirada global en las finanzas, las comunicaciones, etc. El sentido ontológico de lo nuevo, la categoría de las nuevas prácticas letradas alude a las prácticas mediadas por formas de texto "postipográficas" o multimodales.

\section{La concepción de la lectura en los Lineamientos curriculares de lengua castellana del Ministerio de Educación Nacional}

Es justo reconocer que los Lineamientos curriculares de lengua castellana constituyeron un valioso esfuerzo del Ministerio de Educación Nacional (MEN) por recopilar y articular los desarrollos de disciplinas como el análisis del discurso, la lingüística del texto y la psicolingüística, así como de la pedagogía para desarrollar una propuesta de enseñanza de la lengua y la literatura de mayor calidad y acorde con las nuevas exigencias de la sociedad contemporánea.

Sin embargo, es necesario someter a consideración los presupuestos teóricos y metodológicos de las concepciones de lectura y escritura que subyacen en los discursos educativos oficiales. La concepción de lectura que se defiende en los Lineamientos curriculares del MEN (1998, p. 72), documento que orienta aún la política curricular en lengua castellana en Colombia, es la psicolingüística:

Leer es un proceso de construcción de significados a partir de la interacción entre el texto, el contexto y el lector. El significado, a diferencia de lo que sostenía el modelo perceptivo motriz de la lectura, no está solo en el texto, tampoco en el contexto ni en el lector, sino en la interacción de los tres factores, que son los que, juntos, determinan la comprensión. (Documento Lineamientos Curriculares, 1998, p. 72)

Los autores de este documento sostienen que el núcleo del proceso lector es la comprensión lectora, en la interacción entre el texto, el contexto y el lector. Una primera fase de este proceso consistiría en dar cuenta del sentido literal del texto; la segunda fase es la creación lo cual significa aportarle al texto, enriquecerlo y recrearlo. En la construcción de este proceso se activan una serie de estrategias como el muestreo, la predicción, la inferencia. Se definen, además, los propósitos de la lectura, se tiene en cuenta el nivel de conocimiento previo de los lectores, así como el nivel de desarrollo cognitivo de los sujetos, su situación emocional, además de sus competencias con el lenguaje (gramatical, textual, semántica y pragmática). Por otra parte, se adentra en el conocimiento del texto como expresión de reglas tales como la adecuación, la coherencia, la cohesión y la corrección gramatical.

Estos referentes teóricos para pensar categorías sobre la lectura y la escritura resultan insuficientes en el contexto actual de la expansión de las tecnologías digitales. Los aportes de la teoría crítica (Horkheimer, Habermas y la Escuela de Fráncfort, con su crítica al positivismo científico y la lucha contra un trabajo esclavizante y alienante), de la pedagogía crítica, los nuevos estudios de literacidad y del análisis crítico del discurso requieren ser incorporados en un nuevo paradigma sobre las políticas de lectura y escritura a nivel nacional para dar cuenta de los desafíos de la lectura contemporánea.

Como puede observarse, no existe en los Lineamientos una aproximación a las nuevas conceptualizaciones sobre el proceso lector en el contexto de las tecnologías digitales y los referentes teóricos resultan hoy poco eficaces para dar cuenta de la complejidad de la lectura en una sociedad que ha cambiado en todos los ámbitos por influencia de las tecnologías electrónicas. Solo encontramos una breve alusión a lo "crítico" en el apartado "4.3.1. El diálogo entre los textos: Una posibilidad de trabajo con la literatura":

Por lectura crítica ha de entenderse un saber proponer interpretaciones en profundidad de los textos. La interpretación en profundidad implica un proceso de lectura que va desde el nivel primario, o lectura literal, pasa por un nivel secundario, o lectura inferencial y converge en un nivel crítico-intertextual. Este tercer nivel, operado en un lector competente, se caracteriza 
porque desde allí se generan las relaciones dialógicas entre textos de diversa clase, y no sólo los literarios. (Lineamientos curriculares de lengua castellana, 1998, p. 81)

Podemos notar que se trata de una interpretación desfasada a nivel teórico. Hay que tener presente que este documento fue publicado en $1998 \mathrm{y}$ no se avizoraban aún los profundos cambios de la cultura escrita contemporánea, así como tampoco los aportes de corrientes como la teoría crítica, los nuevos estudios de literacidad, la pedagogía crítica, la multimodalidad, el análisis crítico del discurso y las literacidades digitales. Este tipo de modelos de lectura centrados en el cumplimiento de etapas han sido discutidos desde la perspectiva de la alfabetización crítica y los nuevos estudios de literacidad en los cuales se ha concluido que el significado no reside en el texto o en el lector, o en la confluencia de ambos, sino que al contrario el contexto social y cultural juega un papel cada vez más determinante en la comprensión y en el develamiento de las ideologías que transmiten los diversos tipos de textos que se encuentran en la cultura. También desempeñan un rol profundamente relevante en la apropiación de la cultura escrita, la identidad de los lectores, su historia de vida letrada, sus intereses, deseos, temores y necesidades, de acuerdo con la concepción de la literacidad crítica (lectura y escritura críticas) que se ha defendido en este artículo.

\section{Lectura crítica en las pruebas ICFES Saber 11 (2014)}

Uno de los cambios más relevantes que se propone implementar en el examen Saber 11. ${ }^{\circ}$ es la incorporación de la prueba "Lectura crítica", la cual es el resultado de la fusión de las pruebas de lenguaje y de filosofía del examen vigente. Los autores del documento de justificación de "La prueba de la lectura crítica" (2014) explican brevemente algunas consideraciones que avalan esta propuesta y plantean cuáles son sus alcances. En primer lugar, se expone la evolución reciente de las pruebas de lenguaje y de filosofía de Saber $11 .^{\circ}$. En segundo lugar, se defiende la propuesta de fusión de estas pruebas en una de lectura crítica. Finalmente, se presentan algunos ejemplos que servirán para ilustrar la estructura y los contenidos de la nueva prueba propuesta.

De acuerdo con el apartado "Prueba de lectura crítica", la evaluación de las competencias en lenguaje y filosofía integradas en una sola prueba de lectura crítica contribuiría a una transformación que se viene promoviendo de tiempo atrás, la cual se orienta a fortalecer la evaluación de capacidades interpretativas y de razonamiento lógico a partir de un texto y evitar la de conocimientos declarativos. La prueba pretende recoger lo que se evalúa actualmente en lenguaje y en filosofía, y cubriría los estándares de lenguaje para el nivel de la educación media.

De acuerdo con este texto del Ministerio de Educación Nacional, la primera competencia es la de identificar y entender los contenidos explícitos de un texto. Dicho de otra manera, el estudiante debe identificar los eventos, las ideas, las afirmaciones y los demás elementos locales presentes en el texto, y debe entender esos elementos. La segunda competencia es la de comprender cómo se articulan las partes de un texto para darle un sentido global. El estudiante debe comprender la manera como se relacionan los elementos locales de un texto a nivel semántico y formal. La tercera competencia es la de reflexionar a partir de un texto y evaluar su contenido. El estudiante debe, para citar un caso, analizar argumentos, identificar supuestos, advertir implicaciones y reconocer estrategias discursivas. En definitiva, las tres competencias mencionadas se encuentran estrechamente relacionadas entre sí. Para aproximarse críticamente a un texto un estudiante debe, en primer lugar, comprender las unidades locales de sentido. En segundo lugar, debe integrar esa información para darle un sentido global al texto. Y, en tercer lugar, una vez superadas las dos etapas anteriores, debe tomar una postura crítica frente al texto, reflexionando sobre su contenido.

PRUEBA DE LECTURA CRÍTICA (EJEMPLOS DE PREGUNTAS, CUADERNILLO, p. 9-15) Responda las preguntas 26 a 28 de acuerdo con la siguiente información 
A mucha gente le gusta ver en los cuadros lo que también le gustaría ver en la realidad. Se trata de una preferencia perfectamente comprensible. A todos nos atrae lo bello en la naturaleza y agradecemos a los artistas que lo recojan en sus obras. Esos mismos artistas no nos censurarían por nuestros gustos. Cuando el gran artista flamenco Rubens dibujó a su hijo, estaba orgulloso de sus agradables facciones y deseaba que también nosotros admiráramos al pequeño. Pero esta inclinación a los temas bonitos y atractivos puede convertirse en nociva si nos conduce a rechazar obras que representen asuntos menos agradables. El gran pintor alemán Alberto Durero seguramente dibujó a su madre con tanta devoción y cariño como Rubens a su hijo. Su verista estudio de la vejez y la decrepitud puede producirnos tan viva impresión que nos haga apartar los ojos de él y, sin embargo, si reaccionamos contra esta primera aversión, quedaremos recompensados con creces, pues el dibujo de Durero, en su tremenda sinceridad, es una gran obra. En efecto, de pronto descubrimos que la hermosura de un cuadro no reside realmente en la belleza del tema. No sé si los golfillos que el pintor español Murillo se complacía en pintar eran estrictamente bellos o no, pero tal como fueron pintados por él, poseen desde luego gran encanto.

Tomado de: Gombrich, E.H. (2003): Historia del arte. Madrid: Random House Mondadori

26. En el texto, el autor hace referencia a Rubens para mostrar que:

A. a todos nos atrae lo bello y por fortuna el arte lo recoge en la pintura.

B. el público siempre exige que el artista refleje la realidad en los cuadros.

C. algunos artistas plasman en sus obras lo que nos gusta ver en la realidad.

D. la inclinación en el arte por los temas bonitos y atractivos es bastante nociva.

27. ¿Cuál de los siguientes enunciados expresa un juicio de valor presente en el texto?
A. Mientras Rubens dibujó la juventud, Durero dibujó la vejez.

B. Los golfillos del pintor español Murillo tienen gran encanto.

C. Rubens estaba orgulloso de su hijo y deseaba que lo admiráramos.

D. Para el público la hermosura de un cuadro reside en la belleza del tema.

28. ¿Cuál de los siguientes títulos sería el más adecuado para el texto anterior?

A. En defensa del mal gusto en el arte.

B. El arte como modelo de la realidad.

C. La representación de la belleza en el arte.

D. Rubens, Durero y Murillo, el arte de la pintura.

\section{Análisis}

Tomamos este ejemplo para analizar si en efecto se están implementando estrategias de lectura crítica, tanto en la selección de los textos como en el desarrollo de las preguntas. En primer lugar, se observa que no solo en este ejemplo de texto, sino en los demás textos del documento "Ejemplos de preguntas 2014 " se sigue trabajando con fragmentos y adaptaciones y no se presentan textos completos, lo cual sería lo ideal. No es necesario que sean demasiado extensos. El trabajo con textos modelo, combinados con la enseñanza en general y los procedimientos específicos para la enseñanza de la lectura y la escritura ha demostrado ser eficaz en el desarrollo del pensamiento crítico en la composición escrita (Smagorinsky, 1992).

Al contrario, el trabajo con fragmentos y adaptaciones de textos descontextualiza, de algún modo, el texto porque no permite identificar cabalmente la estructura, el propósito y la ideología que subyace en él, la identidad del autor, etc. Estos son aspectos que deberían evaluarse en una dimensión crítica de la lectura.

En segundo lugar, la introducción de textos de filosofía (así se presenten como fragmentos de artículos periodísticos), y que estos ocupen el mayor 
porcentaje (66\%) de los textos de la prueba puede sesgar los resultados, en detrimento de alumnos provenientes de colegios públicos y privados de estratos bajos, porque en la vida escolar y en la vida diaria estos alumnos se enfrentan en menor medida a este tipo de textos, sobre todo si no pertenecen a las élites (en algunos planteles privados de estratos altos, los estudiantes comienzan a cursar Filosofía y Teoría del Conocimiento en 9. ${ }^{\circ}$ grado). La educación humanística, centrada en el estudio de la filosofía, La literatura y la historia ha constituido un privilegio de las clases altas en nuestro país.

Los lectores de la sociedad globalizada están expuestos a una gran variedad de textos auténticos en formatos multimodales, caricaturas, memes, además de discursos de tipo periodístico, de divulgación de la ciencia y los más recientes desarrollos de la tecnologías, del mundo laboral y aquellos relacionados con los conflictos identitarios, con las tribus urbanas, y los diversos colectivos sociales a los cuales pertenecen muchos de ellos, además, giran alrededor de las identidades juveniles, sexuales, políticas, etc. Estos discursos o textos auténticos pueden resultar más interesantes para ellos, más cercanos a sus deseos y necesidades de información y conocimiento y dar cuenta de una sociedad más plural y democrática.

Por otra parte, estos textos podrían aprovecharse mejor para develar los sesgos e ideologías presentes en estos, para desechar la basura textual, para identificar diferentes tipos de estructuras textuales que combinan discurso escrito, imagen y sonido, entre otros aspectos concomitantes. Quizás más adelante haya que pensar que el desarrollo de estas pruebas se realice a través de las pantallas de un computador conectado a Internet y esto facilite el acceso a la diversidad textual a la que se enfrentan los jóvenes de la era digital.

Reconocemos, en todo caso, como un aspecto positivo la inclusión en la antología de textos de una infografía titulada "Los traumatismos causados por el tránsito: los hechos de la Organización Mundial de la Salud" (fuente: Informe sobre la seguridad vial, 2013) porque se acerca más a la realidad de la multimodalidad a la que se enfrentan a diario los lectores de la sociedad contemporánea. Sin embargo, consideramos que no es suficiente incluir un solo texto auténtico dentro de los modelos de la prueba de lectura crítica.

\section{Conclusiones}

Ante la imprevisibilidad de las políticas curriculares y de evaluación del Ministerio de Educación Nacional y en el contexto de los profundos cambios propiciados por los soportes digitales (computadores, tabletas, teléfonos celulares, etc.) y de la lectura y la escritura en línea, se hace imperativo reconocer por un lado la centralidad del discurso en estas transformaciones, y por el otro, debatir y construir nuevas aproximaciones teóricas a la lectura contemporánea.

Las profundas transformaciones sociales, económicas y políticas que han traído consigo la globalización y las tecnologías digitales han tenido un gran impacto en la vida privada y pública de las personas. El lenguaje como discurso juega un papel fundamental en estos cambios contemporáneos, como sostienen Barton y Lee (2013), los cuales son principalmente cambios en la construcción de significado y en la comunicación. El lenguaje como discurso resulta central en el proceso de dar forma a estos cambios en la vida y en las experiencias de los sujetos. De igual manera, se transforma y afecta por estos devenires.

Los conceptos de lenguaje dominantes han sido retados por los modos de vivir y comunicar en la era digital. En consecuencia, los conceptos de lector, autor y audiencia, así como las fronteras entre lo oral y lo escrito, y los procesos de lectura y escritura están experimentando un proceso de redefinición, sin precedentes en la cultura contemporánea.

Todos los referentes teóricos que hemos expuesto a lo largo de este artículo coinciden en afirmar que los modelos lingüísticos y psicolingüístico resultan insuficientes para explicar los cambios de la lectura y la escritura contemporáneas, y que se hace necesario adoptar un paradigma más sociocultural y crítico de la literacidad, denominado alfabetización 
crítica o literacidad crítica, para poder navegar en la sociedad digital y para avanzar en la construcción de la democracia.

Como señala Morrell (2008), la opinión pública y nuestros estudiantes reciben una gran cantidad de información a través de los medios, de las redes sociales, de las corporaciones y las instituciones educativas. Esta información está cargada de ideologías y sesgos que pueden llegar a ejercer violencia simbólica, la cual lleva a la alienación y a diferentes formas de depresión. Por lo tanto, la lectura crítica es fundamental para analizar, poner en discusión y contraargumentar las ideologías que subyacen en el lenguaje y los textos de una sociedad basada en la información y el conocimiento. Así, para comprendernos a nosotros mismos, debemos comprender el papel del lenguaje como discurso y de los textos en la construcción de la identidad del yo y de lo social.

La apertura de la dimensión crítica de la lectura crítica en la educación colombiana es un proceso que se encuentra en un grado muy incipiente, como lo hemos podido evidenciar a través de un primer ejercicio de análisis de la prueba de lectura crítica de las Pruebas Saber 11 (2014) y de la exposición teórica que hemos desarrollado en el artículo. Los currículos y discursos oficiales siguen reproduciendo el paradigma del enfoque psicolingüístico, desconociendo los avances de disciplinas como los nuevos estudios de literacidad (nuevos estudios de cultura escrita) y enfoques más socioculturales y críticos, necesarios para poder navegar con timón crítico en la sociedad digitalizada. Son necesarios más estudios sobre la fundamentación teórica y pedagógica de la "Prueba de lectura crítica", así como nuevas aproximaciones a la enseñanza de la lectura de los textos académicos y de los textos auténticos que circulan en Internet y las redes sociales para poder tener una comprensión más cabal de los ajustes que deben tener este tipo de exámenes de competencias.

\section{Referencias}

Aliagas, C. (2011). El desinterès lector adolescent. Estudi de cas de les practiques i identitats lletrades d'e una colla de amics des de la perspectiva dels Nous studies de Literacitat (Tesis doctoral). Universitat Pompeu Fabra. Barcelona. Recuperada en diciembre de 2011 desde http:// www.tdx.cesca.es

Aliagas, C., Castellà, J. M., y Cassany, D. (2009). Aunque lea poco, yo sé que soy listo. Estudio de caso sobre un adolescente que no lee literatura. Revista OCNOS 5, 97-112.

Barthes, R. (1980). S/Z. México: Siglo XXI.

Barton, D. (1994/2007). Literacy. An introduction to the ecology of written language [2. ${ }^{\mathrm{a}} \mathrm{Ed}$.]. Oxford: Blackwell.

Barton, D., Hamilton, M., e Ivanic, R. (eds.) (2000). Situated Literacies. Reading and Writing in Context. Londres/Nueva York: Routledge.

Barton, D., y Lee, C. (2013). Language Online. Investigating Digital Texts and Practices. Londres/Nueva York: Routledge.

Bauman, Z. (2006). Vida líquida. Barcelona: Paidós Estado y Sociedad.

Bauman, Z. (2010). Identidad. Conversaciones con Benedetto Vecchi. Buenos Aires: Losada.

Berkenkotter, C. (1984). Student writers and their sense of authority over texts. College Composition and Communication, 35(3), 312-319.

Berkenkotter, C., y Huckin, T. N. (1995). Genre Knowledge in Disciplinary Communication: Cognition/Culture/ Power. Hillsdale, NJ: Lawrence Erlbaum.

Bloome, D., Power Carter, S., Cristian Morton, B., Otto, S., y Shuart-Faris, N. (2005). Discourse analysis and the study of classroom language and literacy events. A microethnographic perspective. New Jersey: Lawrence Erlbaum.

Bolter, D. J. (1990). Writing Space. Hillsdale, N.J.: Lawrence Erlbaum.

Brice Heath, Sh., y Street, B. (2008). Ethnography. Approaches to Language and Literacy Research. New York: Teachers College Press.

Cassany, D. (2006). Tras las líneas. Sobre la lectura contemporánea. Barcelona: Anagrama.

Cassany, D. (2012). En_línea. Leer y escribir en la red. Barcelona: Anagrama.

Coll, C. (2005). Lectura y alfabetismo en la sociedad de la información. Uocpapers, 1, p. 4-9. http://www.uoc. edu/uocpapers/1/dt/esp/coll.pdf. Recuperado el día 22 de mayo de 2015.

Chartier, R. (2001). Muerte o transfiguración del lector. En 26. ${ }^{\circ}$ Congreso de la Unión Internacional de Editores 
(del 1 al 4 de mayo de 2000: Buenos Aires). [En línea, Fecha de consulta: 29 de marzo de 2015].

Delors, J. (1996). Informe a la UNESCO de la Comisión Internacional sobre la educación para el siglo XXI. La educación encierra un Tesoro. Madrid: Santillana Unesco.

Derrida, J. (2005). De la gramatología. México: Siglo XXI.

Fairclough, N. (1992a). Discourse and social change. Cambridge: Polity Press.

Fairclough, N (1992b). Critical language awareness. London: Logman.

Fairclough, N. (2010). Critical discourse analysis. The critical study of language. Edinburgh: Longman Applied Linguistics.

Freire, P., y Macedo, D. (1989). Alfabetización. Lectura de la palabra y lectura de la realidad. Barcelona: Paidós.

Foucault, M. (2009). La arqueología del saber. Madrid: Siglo XXI.

Gee, J. P. (1996). Social linguistics and literacies: ideology in discourses. Basingstoke: Falmer Press [Versión española: La ideología en los discursos. Barcelona: Gedisa. 2005].

Gewerc, A. (Coord.) (2014). Conocimiento, tecnologías y enseñanza: políticas y prácticas universitarias. Barcelona: Graó.

ICFES, Saber 11 (2014). Publicación 2014. Ejemplos de preguntas. Bogotá: Instituto Colombiano para la Evaluación de la Educación. Ministerio de Educación Nacional.

ICFES, Saber 11 (2013). Sistema nacional de evaluación estandarizada de la educación. Alineación del examen Saber 11. Bogotá: Instituto Colombiano para la Evaluación de la Educación. Ministerio de Educación Nacional.

Ivanic, R. (1998). Writing and identity. The discoursal construction of identity in academic writing. Amsterdam: John Benjamins Publishing.

Jones, C., Turner, J., y Street, B. (eds.) (1999). Students writing in the university. Cultural and epistemological issues. Amsterdam/Philadelphia: John Benjamins Publishing.

Kress, G. (2003). Literacy in the new media age. Londres/ Nueva York: Routledge.

Kruse, P. (2010). Wie die Netzwerke Wirschaft und Gelleschaft revolutionieren. Charla en You Tube, en _l. En Cassany, D. (2012), p- 31-33
Landow, G. (1995). Hipertexto. La convergencia de la teoría crítica contemporánea y la tecnología. Barcelona: Paidós.

Lankshear, C., y Knobel, M. (2010). Nuevos alfabetismos. Su práctica cotidiana y el aprendizaje en el aula. Madrid: Morata [Título original: New Literacies: Open University Press].

Lea, M., y Stierer, B. (Eds.) (1999). New contexts for student writing in higher education. Buckingham, UK: Open University Press/Higher Education Research Education.

Lewis, C., Enciso, P., y Moje, E. (Eds.) (2007). Identity, agency and power: Reframing sociocultural research on literacy. Mahwah, NJ: Erlbaum.

Libâneo, J. C. (2013). ¿Adiós professor, adios profesora? Nuevas exigencies educativas y nueva profesión docente. Barcelona: Octaedro.

Lillis, Th. (2001). Student writing. Access, regulation, desire. London and New York. Editorial Routledge.

Ministerio de Educación Nacional (MEN) (1998). Lineamientos Curriculares en Lengua Castellana Bogotá: Ed. Magisterio.

McLuhan, M. (1967). The medium is the massage. Harmondsworth: Penguin Books.

Martínez, J. B. (Coord.) (2012). Innovación en la universidad. Prácticas, políticas y retóricas. Barcelona: Graó.

Mendoza, A. (2012) (Coordinador). Leer hipertextos. Del marco hipertextual a la formación del lector literario. Barcelona: Octaedro.

Moliner, M. (2007). Diccionario de uso del español. Madrid: Gredos.

Montero, L. (2014). Convivir con los cambios. Ser profesor y profesora en la universidad en tiempos convulsos. En A. Gewerc (coord.), Conocimiento, tecnologías $y$ enseñanza: políticas y prácticas universitarias (pp. 53-70). Barcelona: Graó.

Morrell, E. (2008). Critical literacy and urban youth. Nueva York/Londres: Routledge.

Pons Pablos, J. (2010). Universidad y sociedad del conocimiento.Las competencias informacionales y digitales. RUSC. Universities and Knowledge Society Journal, $7(2)$.

Prensky, M. (2001). Digital Natives, Digital Inmigrants. On the Horizon, 9, 5.

Prensky, M. (2010). Teaching digital natives. Partnering for real learning. Thousands Oaks: Corwin. 
Prensky, M. (2012). From digital natives to digital wisdom. Hopeful Essays for 21st Century Learning. Thousands Oaks: Corwin.

Rizvi, F., y Lingard, B. (2013). Políticas educativas en un mundo globalizado. Madrid: Morata.

Smagorinsky, P. (1992). Cómo influye en los escritores la lectura de composiciones modelo. En Irwin, J. y Doyle, M. A. (comp.). Conexiones entre lectura y escritura. Aprendiendo de la investigación (p. 195214). Buenos Aires: Aique.

Street, B. (1984). Literacy in theory and practice. Cambridge: Cambridge University Press.

Street, B. (Ed.) (1993). Cross-Cultural approaches to literacy. Cambridge. Cambridge University Press.

Street, B. (1995). Social Literacies: Critical approaches to literacy in development, education and ethnography. London: Longman.

Tejada, H., y Vargas, A. (2007). Hacia una integración de la literacidad crítica, la literacidad funcional y la literacidad cultural. Lenguaje, 35(2), 196-219.

Turner, J. (1999). Academic Literacy and the Discourse of Transparency. En C. Jones, C. Jones, J. Turner y B. Street (eds.), Students writing in the university. Cultural and epistemological issues (p. 149160). Amsterdam/Philadelphia: John Benjamins Publishing.
Vargas Franco, A. (2015a). La universidad y la sociedad del conocimiento: el caso de la lectura y la escritura (Documento inédito).

Vargas Franco, A. (2015b). Escritura académica en la universidad: un enfoque sociocultural. Estudio de caso de un estudiante maduro debutante en la literacidad académica en un programa de formación de una universidad pública colombiana. Medellín: Fondo Editorial Instituto Tecnológico Metropolitano.

Wodak, R. (2003). De qué trata el análisis crítico del discurso (ACD). Resumen de su historia, sus conceptos fundamentales y sus desarrollos. En R. Wodak y M. Meyer (comps.). Métodos de análisis crítico del discurso (pp. 17-33). Barcelona: Gedisa.

Zavala, V. (2009). ¿Quién está diciendo eso?: literacidad académica, identidad y poder en la educación superior". En J. Kalman y B. Street (Coords.), Lectura, escritura y matemáticas como prácticas sociales ( $\mathrm{p}$. 348-363). Diálogos con América Latina. México: CEFRAL, Siglo XXI.

Zavala, V., y Córdova, G. (2010). Decir y callar. Lenguaje, equidad y poder en la universidad peruana. Lima: Pontificia Universidad Católica del Perú.

Zavala, V. (2011). La escritura académica y la agencia de los sujetos. Cuadernos Comillas. Revista Internacional de Aprendizaje del Español, monográfico 1, 52-66. 